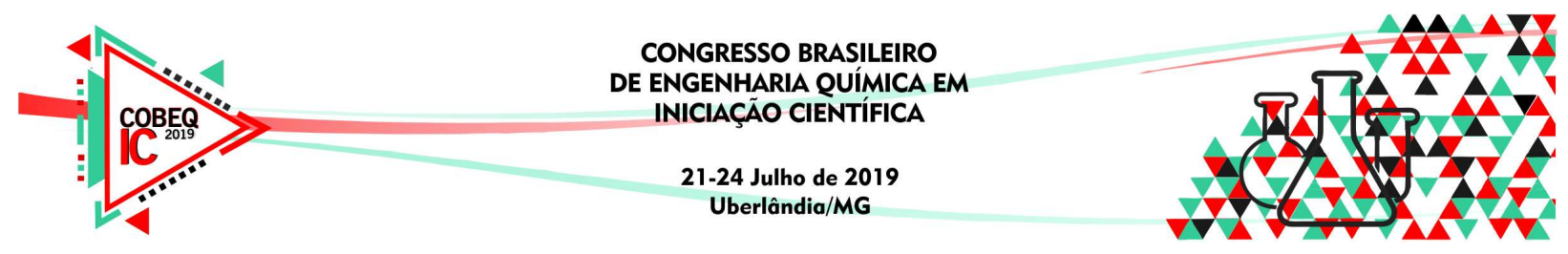

\title{
ESTUDO DA CINÉTICA DE FLOTAÇÃO CATIÔNICA DE REJEITOS DE MINÉRIO DE FERRO
}

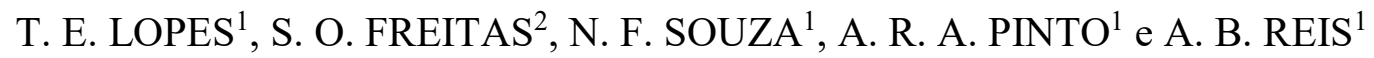 \\ ${ }^{1}$ Universidade Federal dos Vales do Jequitinhonha e Mucuri, Instituto de Ciência e \\ Tecnologia (UFVJM) - Curso de Engenharia Química \\ ${ }^{2}$ Universidade Federal dos Vales do Jequitinhonha e Mucuri, Instituto de Ciência e \\ Tecnologia (UFVJM) - Curso de Engenharia Geológica \\ E-mail para contato: tiagoeugenio868@gmail.com
}

\begin{abstract}
RESUMO - A flotação é uma operação unitária utilizada para separar partículas hidrofóbicas de partículas hidrofílicas. Essa técnica consiste em adicionar bolhas de ar ao meio, o que faz com que as partículas hidrofóbicas em suspensão no líquido passem a aderir-se a essas bolhas. A espuma formada pode então ser removida, arrastando consigo as partículas de impurezas. Este trabalho apresenta particular interesse de estudo experimental acerca do processo de flotação reversa com o intuito de recuperar minerais de interesse, como por exemplo, minerais ferro, presentes em rejeitos da indústria de mineração, visando sobretudo o reaproveitamento em aplicações futuras.
\end{abstract}

\section{INTRODUÇÃO}

A mineração sempre foi uma área de destaque na economia brasileira e está presente nas atividades sociopolíticas do país desde 1500 até os dias de hoje, tendo passado por três regimes políticos diferentes, Colônia, Império e República (FERNANDES e ARAÚJO, 2016). A demanda por recursos minerais disparou nesses últimos anos, devido ao rápido crescimento populacional e volume de exportações, observado nos últimos anos. Como esses materiais não são renováveis, muitas jazidas de alta concentração de minério já estão em sua capacidade máxima de extração, fazendo com que mineradoras busquem outras formas de tratamento mineral mais complexos e com exploração de baixos teores (PENNA et al., 2003) como o estudo de processo de separação e beneficiamento.

Com o avanço das tecnologias, as indústrias minerais estão sujeitas a produzir materiais mais específicos e com menores custos. Neste sentido, a flotação é um processo de concentração mineral desenvolvido para tentar recuperar os minérios de menores teores que são perdidos na extração do mineral de maior teor (PENNA et al., 2003). No processo de flotação mineral, o ar é borbulhado através de uma polpa de minério, e reagentes com funções específicas são adicionados à polpa. No caso da flotação de minério de ferro, esses reagentes tem o objetivo de modificar a superfície dos óxidos de ferro ou silicatos para que essas partículas possam seletivamente se aderir nas bolhas de ar para serem conduzidas até a superfície, onde serão removidas em forma de espuma. (LOPES, 2009). Durante a flotação, ocorre o fenômeno de 


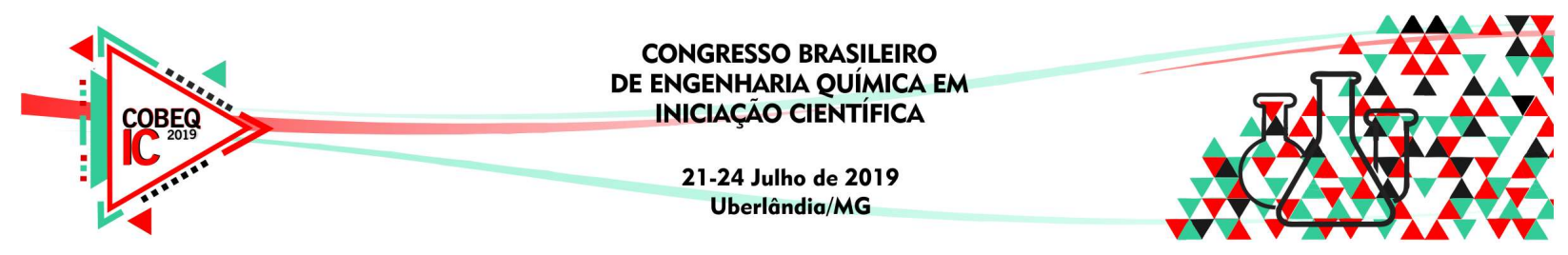

transferência de massa, onde o ar transporta matéria da polpa para a espuma formada (LABIDI et al., 2006). As indústrias de mineração comumente utilizam-se das barragens de rejeitos, que são estruturas construídas visando a disposição dos materiais não aproveitados, tendo normas intrínsecas para sua implantação, impedindo que esses rejeitos infiltrem no solo e nos lençóis freáticos contaminando o meio com metais pesados e substâncias nocivas (IBRAM, 2016).

Em novembro de 2015 a barragem de Fundão, da mineradora Samarco, se rompeu liberando um volume aproximado de 34 milhões de metros cúbicos de lama, contendo rejeitos de mineração (FREITAS et al., 2016). Em relação aos contaminantes inorgânicos associados à lama, foram observados elevados teores de óxido de ferro, manganês e sílica. Em janeiro de 2019 uma nova barragem de rejeitos de minério de ferro, associada à mineradora Vale S.A., em Brumadinho (MG) também se rompeu (PEREIRA et al., 2019). Esses desastres trouxeram prejuízos à sociedade, para o meio físico, biótico e socioeconômico que são imensuráveis (ANGOTTI et al., 2019). Após tais catástrofes, se faz necessário, discussões entre os órgãos competentes, no intuito de se chegar num consenso, visando sobretudo, a implantação de normas de segurança e/ou abolição das barragens de rejeito, tendo com uma das alternativas a busca por destinos mais nobres para os rejeitos gerados no processo de beneficiamento.

No âmbito desse contexto, o presente trabalho teve como objetivo principal, iniciar estudos no intuito de promover a recuperação dos minerais presentes em amostras de rejeitos da indústria de mineração. Para tanto foi realizado estudo acerca da transferência de massa durante o processo de flotação, a partir de um planejamento fatorial do tipo $2^{2}$ tendo como variáveis a concentração da polpa e a vazão de ar na flotação catiônica reversa como um processo de recuperação, analisando a cinética de transferência de massa, refletida na possibilidade de separação das frações.

\section{MATERIAIS E MÉTODOS}

Nessa seção são retratados os materiais e a metodologia empregada nas práticas laboratoriais para a realização do trabalho que foi no desenvolvido no Laboratório de Engenharia do curso de Engenharia Química da UFVJM.

\subsection{Materiais}

Durante o desenvolvimento do trabalho foram utilizados os seguintes materiais:

- Amostras de rejeito de mineração;

- Amido de milho (comercial) gelatinizado com $\mathrm{NaOH}$, amina $\mathrm{EDA}, \mathrm{HCl}, \mathrm{NaOH}$, água destilada;

- Béquer, bastão de vidro, balão volumétrico;

- Balança analítica, estufa, módulo de flotação horizontal;

Para o processo de flotação reversa foram utilizadas amostras de rejeito de mineração cedidos pela empresa Samarco coletada na Usina de Risoleta Neves, conhecida como Candonga, localizada no município de Santa Cruz do Escalvado-MG. 


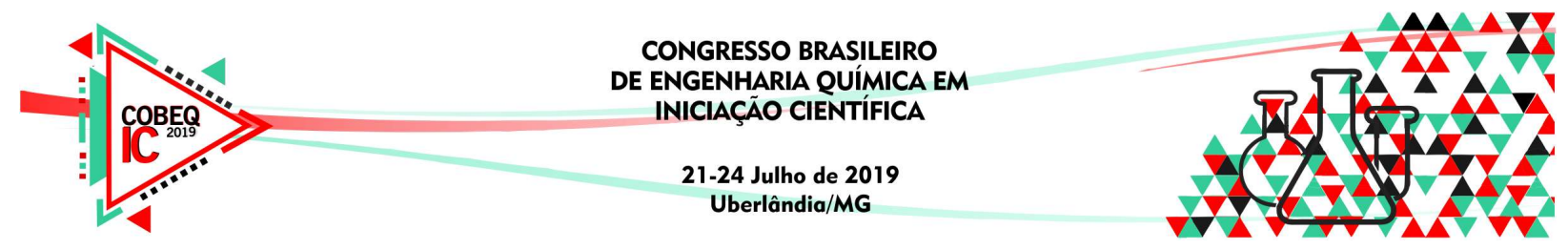

Os experimentos foram realizados em uma célula mecânica, sendo ela um módulo didático "flotador horizontal" da empresa UpControl para a realização da prática, como mostrado na Figura 1.

\subsection{Métodos}

Neste trabalho foi realizado o processo de flotação catiônica reversa com objetivo de recuperar a hematita. A polpa foi ajustada para um de $\mathrm{pH}$ para 10,5, utilizou-se o amido de milho comercial, como depressor e amina EDA, como coletor.

Figura 1 - Equipamento utilizado na flotação reversa

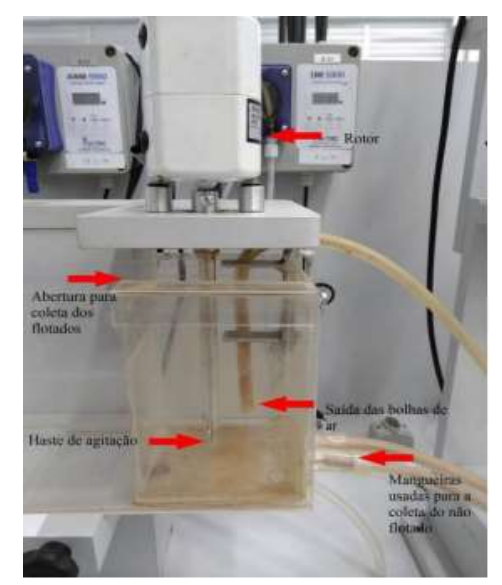

O processo da flotação foi realizado a partir do planejamento fatorial do tipo $2^{2}$ com duas repetições do ponto central, tendo como variáveis manipuladas, a concentração da polpa e a vazão de ar. Os valores adotados no planejamento fatorial podem ser observados na Tabela 1. Os valores das concentrações foram definidos de acordo com a literatura (PIUZZANA et al., 2015). Em cada concentração, o pH da polpa foi corrigido para 10,5, com adição de hidróxido de sódio $(\mathrm{NaOH})$ e ácido clorídrico $(\mathrm{HCl})$, (PIUZZANA et al., 2015). A polpa foi transferida para o flotador, logo após, o rotor foi ligado a uma velocidade de $1500 \mathrm{rpm}$. Para aeração do sistema foi utilizado um compressor com uma vazão de ar comprimido (Tabela 1). Com a polpa em agitação adicionou-se o amido gelatinizado e após 5 minutos, adicionou-se à polpa a amina EDA, e os reagentes introduzidos foram quantificados de acordo com a concentração de cada experimento.

Tabela 1 - Dosagens de depressor e coletor usados nos ensaios de flotação.

\begin{tabular}{|c|c|c|}
\hline Concentrações & $\begin{array}{c}\text { Depressor } \\
(\mathrm{mL})\end{array}$ & $\begin{array}{c}\text { Coletor } \\
(\mathrm{ml})\end{array}$ \\
\hline $25,0 \%$ & 2,50 & 1,00 \\
\hline $37,5 \%$ & 4,70 & 1,88 \\
\hline $50,0 \%$ & 10,00 & 4,00 \\
\hline
\end{tabular}




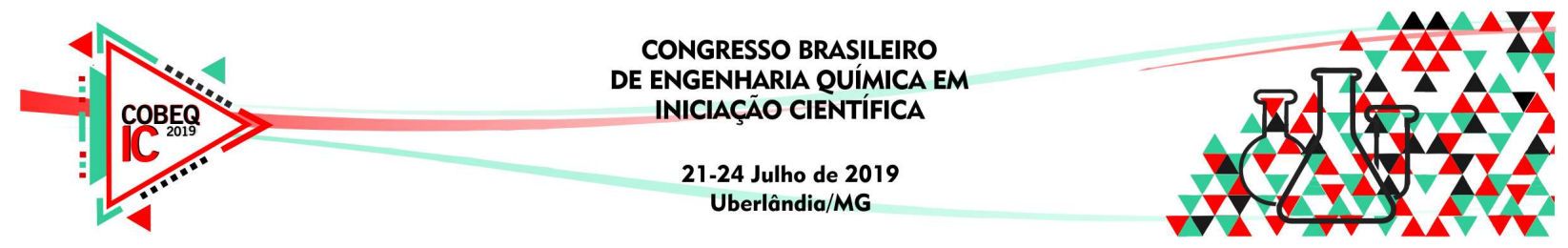

A coleta do concentrado foi feita manualmente a cada minuto durante um intervalo de 8 minuto e, cada amostra de concentrado foi disposta em béqueres. Após o término do experimento, o material coletado foi seco, pesado e, em seguida, foram efetuados os cálculos da massa acumulada.

Tabela 2 - Parâmetros adotados no planejamento $2^{2}$.

\begin{tabular}{|c|c|c|}
\hline Ensaio & $\begin{array}{c}\text { Concentração } \\
\text { de sólidos na } \\
\text { polpa }\end{array}$ & $\begin{array}{c}\text { Vazão de ar } \\
(\mathrm{NL} / \mathrm{h})\end{array}$ \\
\hline 1 & $50,0 \%$ & 200 \\
\hline 2 & $50,0 \%$ & 400 \\
\hline 3 & $25,0 \%$ & 400 \\
\hline 4 & $25,0 \%$ & 200 \\
\hline 5 & $37,5 \%$ & 300 \\
\hline 6 & $37,5 \%$ & 300 \\
\hline
\end{tabular}

\section{RESULTADOS}

Na Figura 2 são mostrados os resultados da cinética de recuperação mássica para cada ensaio do planejamento fatorial, sendo possível observar que o comportamento das curvas é semelhante ao observado na literatura.

Figura 2 - Curva de velocidade de transferência de massa.

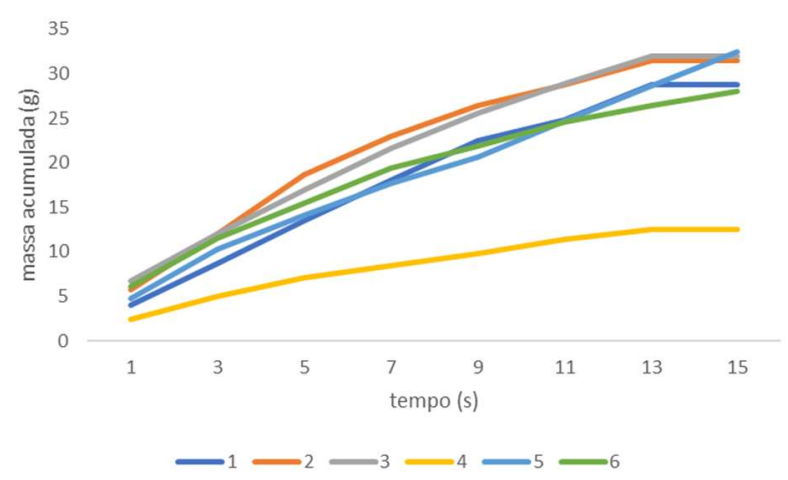

Comparando os experimentos 1 e 2, nos quais o fator variado é a vazão, observou-se que no ensaio 2 a massa acumulada ao longo do tempo se mostrou maior. Fenômeno semelhante ocorreu entre os ensaios 3 e 4. Assim, nota-se que a vazão influência na velocidade da transferência de massa. Em relação à concentração, podemos observar que as curvas 2 e 3 que possuem mesma vazão, porém a concentração do ensaio 2 é maior. Ainda assim as curvas mostram que o acúmulo mássico em ambos os ensaios se mostrou semelhantes.

A curvas 2 e 3 se destacaram em relação às demais quanto a massa acumulada total. Dessa forma, essas curvas tiveram seus pontos iniciais e finais submetidos à análise de FTIR, com objetivo de avaliar as composições em cada ponto. 


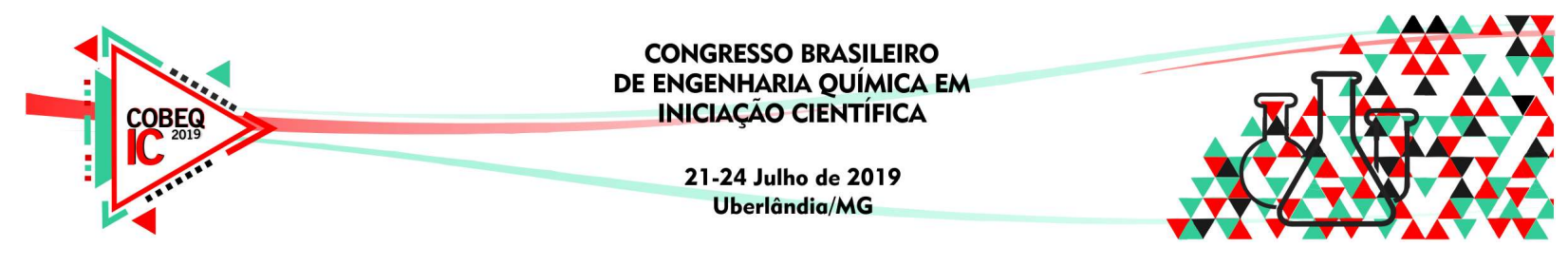

\subsection{Análise de espectroscopia de infravermelho por transformada de Fourier}

O método de espectroscopia de infravermelho por transformada de Fourier (FTIR) consiste em investigar os grupos funcionais presentes na amostra. Desta forma, a Figura 3 demonstra como a análise por infravermelho do rejeito flotado se comporta.

Figura 3 - Análise de espectroscopia de infravermelho por transformada de Fourier.

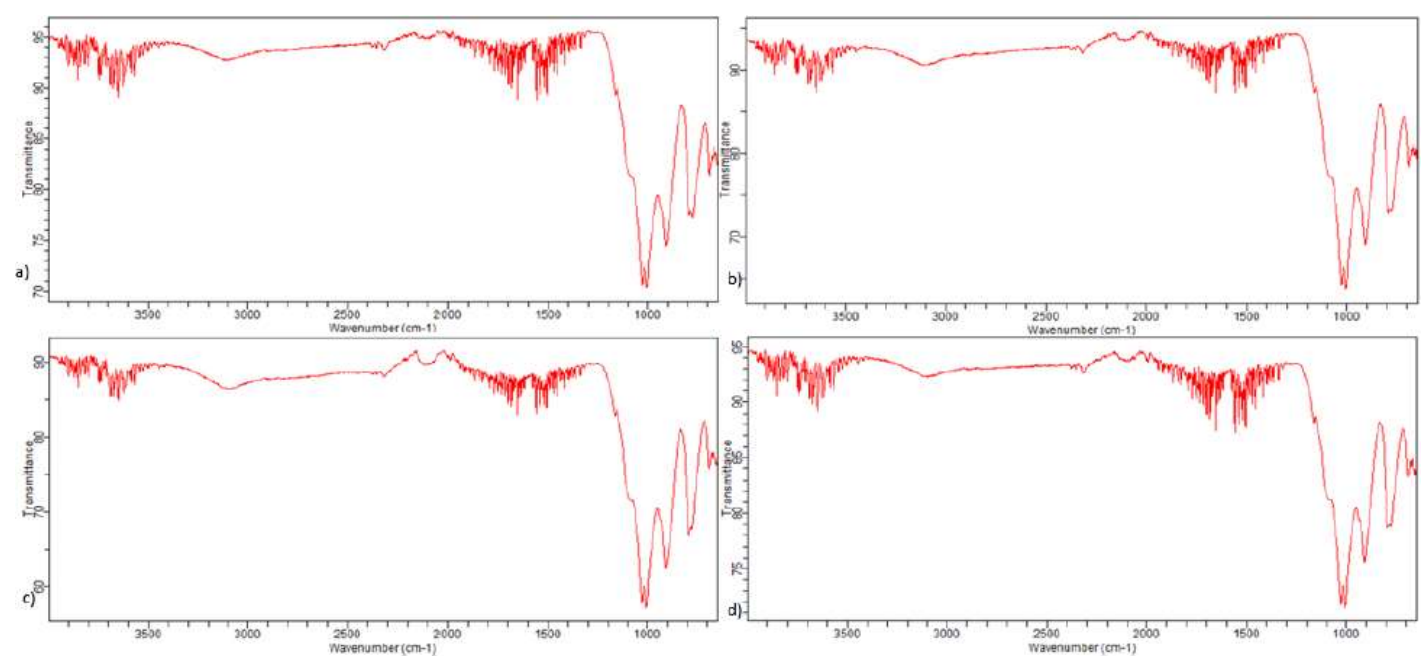

a) Análise do 1' ensaio 3; b) Análise do 7' ensaio 3; c) Análise 1' ensaio 2; d) Análise 8' ensaio 2.

Segundo Lopes (2009), a composição mineralógica do rejeito do minério de ferro apresenta entre diversos compostos, hematita $\left(\mathrm{Fe}_{2} \mathrm{O}_{3}\right)$ e quartzo $\left(\mathrm{SiO}_{2}\right)$. Esses componentes são os principais alvos da flotação catiônica. Os resultados obtidos na análise FTIR (Figura 3), mostram que nos ensaios 2 e 3 tanto no primeiro ponto quanto no último, existe a presença de hematita e quartzo.

De acordo com a literatura, nas análises de infravermelho, as bandas que ocorrem entre 1000 a $1100 \mathrm{~cm}^{-1}$ é caracterizada pelo quartzo $\left(\mathrm{SiO}_{2}\right)$ (AWADH, 2019). Segundo Cardoso (2018), as bandas entre 700 a $900 \mathrm{~cm}^{-1}$ está caracterizado hematita $\left(\mathrm{Fe}_{2} \mathrm{O}_{3}\right)$. Pode-se perceber, que essa qualificação está de acordo com o esperado.

\section{CONCLUSÃO}

A partir da realização do ensaio de flotação por espuma, foi possível observar que este é um método altamente versátil para a separação física de partículas com base nas diferenças na capacidade das bolhas de ar aderirem seletivamente às superfícies minerais específicas na polpa.

Uma observação qualitativa de influência da vazão na quantidade de massa acumulada foi realizada, onde, constatou-se que maiores vazões levam a um maior acúmulo de massa. O mesmo não pode ser observado para a concentração, uma vez que seu comportamento não se mostra padrão quando são variadas as concentrações e fixadas as vazões. Análises de espectroscopia de infravermelho por transformada de Fourier foram realizadas nos ensaios que 


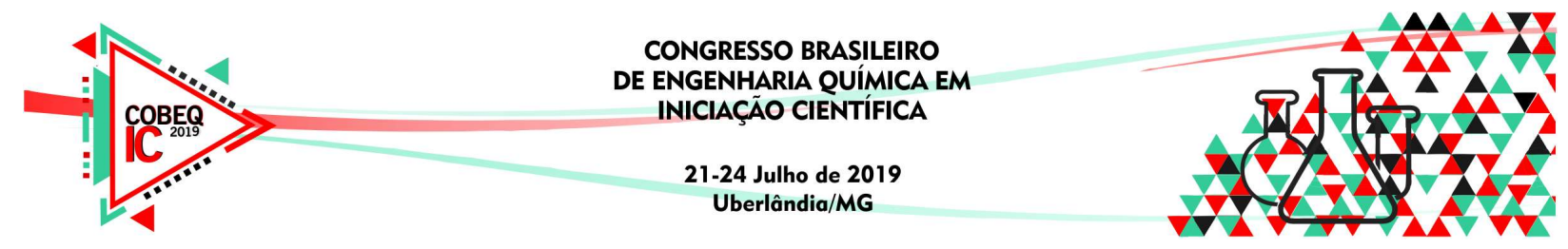

apresentaram maiores valores de massa acumulada, onde, com base na literatura os picos apresentaram características dentro do esperado. Notou-se que para as amostras que tiveram maior acúmulo de massa, provavelmente está relacionado aos picos do FTIR, pois ocorreu maior estiramento assimétrico das ligações, ou seja, maior presença e quantidade do quartzo $\left(\mathrm{SiO}_{2}\right)$ e da hematita $\left(\mathrm{Fe}_{2} \mathrm{O}_{3}\right)$. Vale ressaltar que, em andamento, estão sendo realizados estudos acerca da influência das variáveis de vazão e concentração na composição do flotado.

\section{REFERÊNCIAS}

ANGOTTI, M.; FERREIRA, A. C. S., EUGENIO, T. C. P. Full cost accounting e contabilidade dialógica aplicados para avaliação da (in)sustentabilidade da mineração: o caso de Congonhas (MG). Universidade Federal do Rio de Janeiro, 2019.

AWADH, S. M.; YASEEN, Z. M. Investigation of silica polymorphs stratified in siliceous geode using FTIR and XRD methods. Materials Chemistry and Physics, v. 228, p. 45-50, 2019.

CARDOSO, E. Ri. et al. Nanotubos de carbono decorados com óxido de ferro aplicados a sensores de gás. 2018. Dissertação de Mestrado. Universidade Tecnológica Federal do Paraná.

FERNANDES, F. R. C.; ARAUJO, E. R. Mineração no Brasil: crescimento econômico e conflitos ambientais.

FREITAS, C. M.; SILVA, M. A.; MENEZES, F. C. O desastre na barragem de mineração da Samarco - fratura exposta dos limites do Brasil na redução de risco de desastres. Cienc. Cult. vol.68, no.3, São Paulo, July/Sept. 2016.

IBRAM - Instituto Brasileiro de Mineração. Gestão e Manejo de Rejeitos da Mineração. Organizador: Instituto Brasileiro de Mineração. 1.ed. Brasília: IBRAM, 2016.

LABIDI, J. et al. Predicting flotation efficiency using neural networks. Chem. Eng. and Processing: Process Intensification, v. 46, n. 4, p. 314-322, 2007.

LOPES, G. M. Flotação direta de minério de ferro. 2009. 176 f. Dissertação (Mestrado em Engenharia Mineral) - Universidade Federal de Ouro Preto, Ouro Preto, 2009.

PENNA, R; OLIVEIRA, M. L. M.; VALADAO, G. E. S.; PERES, A. E. C. Estudo comparativo entre dois sistemas de aeração de coluna de flotação. Rem: Revista Escola de Minas. 2003, vol.56, n.3, p.195-200.

PEREIRA, L. F.; CRUZ, G. B.; GUIMARÃES, R. M. F. Impactos do rompimento da barragem de rejeitos de Brumadinho, Brasil: uma análise baseada nas mudanças de cobertura da terra. Journal of Environmental Analysis and Progress, v. 4, n. 2, p. 122-129, 2019

PIUZZANA, G; MACHADO, H; ETRUSCO, I; BIGÃO, L; LÉLIS, M; DINALLI, R. Flotação. Faculdade de Engenharia da Universidade Estadual de Minas Gerais, João Monlevade-MG, 2015. 